\title{
Pica in the Pregnancy and Related Psychological Aspects
}

\author{
Ana Cristina Barros da Cunha ${ }^{1}$ \\ Departamento de Psicologia Clínica, Instituto de Psicologia, Universidade Federal \\ do Rio de Janeiro, Rio de Janeiro, RJ, Brazil \\ Programa de Mestrado Profissional em Saúde Perinatal da Maternidade Escola \\ da Universidade Federal do Rio de Janeiro, Rio de Janeiro, RJ, Brasil \\ Programa de Pós-Graduação em Psicologia, Universidade Federal do Espírito Santo, \\ Vitória, ES, Brazil \\ Solange Frid Patricio \\ Maternidade Escola da Universidade Federal do Rio de Janeiro, Rio de Janeiro, RJ, Brazil \\ Programa de Pós-Graduação em Saúde da Criança e da Mulher, Instituto Fernandes \\ Figueiras, Fundação Oswaldo Cruz, Rio de Janeiro, RJ, Brazil

\section{Laila Pires Ferreira Akerman} \\ Paula Sampaio Maynarde \\ Instituto de Psicologia, Universidade Federal do Rio de Janeiro, Rio de Janeiro, RJ, Brazil
}

Claudia Saunders

Programa de Mestrado Profissional em Saúde Perinatal da Maternidade Escola

da Universidade Federal do Rio de Janeiro, Rio de Janeiro, RJ, Brasil

Programa de Pós-Graduação em Nutrição, Instituto de Nutrição Josué de Castro,

Universidade Federal do Rio de Janeiro, Rio de Janeiro, RJ, Brazil

\begin{abstract}
Based on a descriptive and exploratory research design, this study aimed to evaluate emotional (sings of stress, anxiety and depression) and coping indicators in seven pregnant women with diabetes and pica reporting practices. The pica reporting practices in their current pregnancies were identified before they answered the following instruments for psychological evaluation: (a) Inventory of signs and symptoms of stress of Lipp (ISSL), to evaluate stress; (b) BECK Scales, BAI and BDI Inventory, to evaluate anxiety and depression; (c) Scales of Ways of Coping (EMEP), to identify coping strategies to deal with stress; (d) an Interview Guide created for this study. The pregnant women were interviewed individually and their reports were analyzed into macro-categories by the Bardin's methodology. Indicators of stress, anxiety and depression were found in all pregnant women, whose most reported practice was pagofagia (30.8\%) and fruit with salt (30.8\%). The verbal report revealed that all women had a feeling of satisfaction after the practice of pica. Given that the associations between this eating disorder and unfavorable outcomes, it is important to investigate the pica in order to propose a more effective prenatal care in improving the health of the mother-child dyad.
\end{abstract}

Keywords: Pregnancy, diabetes mellitus, Pica, anxiety, depression, coping.

Mailing address: Rua das Laranjeiras, 180, Laranjeiras, Rio de Janeiro, RJ, Brasil 22240-003. E-mail: acbcunha@yahoo.com.br

Financing: Fundação de Amparo à Pesquisa do Estado do Rio de Janeiro (FAPERJ); Programa Institucional de Bolsas de Iniciação Científica (PIBIC)/ Universidade Federal do Rio de Janeiro (UFRJ). 


\section{Picamalácia na Gestação de Risco e Aspectos Psicológicos Relacionados}

\section{Resumo}

Com base em delineamento descritivo e exploratório, objetivou-se avaliar indicadores emocionais (sinais de estresse, ansiedade e depressão) e de enfrentamento (coping) em sete gestantes adultas com Diabetes Mellitus e relato de práticas de picamalácia. A prática de picamalácia na gestação atual foi identificada por meio de entrevista validada, antes das participantes responderem aos instrumentos para avaliação psicológica: (a) Inventário de sinais e sintomas de stress de Lipp (ISSL), para avaliar estresse; (b) Escalas BECK, Inventário BAI e BDI, para avaliar ansiedade e depressão; (c) Escalas Modos de Enfrentamento de Problemas (EMEP), para identificas estratégias de enfrentamento frente ao estresse; e (d) Roteiro de entrevista elaborado para pesquisa. As gestantes foram entrevistadas individualmente e seu relato foi analisado em macro-categorias pela metodologia de Bardin. Indicadores de estresse, ansiedade e depressão foram encontrados em todas as gestantes e as práticas de picamalácia mais referidas foram pagofagia $(30,8 \%)$ e ingestão de fruta com sal $(30,8 \%)$. Todas as gestantes apresentavam em comum uma sensação de satisfação após a prática da picamalácia. Tendo em vista possíveis associações entre este transtorno alimentar e desfechos desfavoráveis, considera-se importante investigar a picamalacia a fim de propor uma assistência pré-natal mais efetiva na melhora da saúde da díade mãe-filho.

Palavras-chave: Gestação, diabetes mellitus, picamalácia, ansiedade, depressão, enfrentamento.

\section{Pica en el Embarazo y Aspectos Psicologicos Relacionados}

\section{Resumen}

Basado en un diseño descriptivo y exploratorio, el objetivo del estudio fue evaluar los indicadores de estrés, ansiedad, depresión y afrontamiento en siete mujeres embarazadas diagnosticadas con diabetes y informes de la pica. La práctica de pica fue identificada a través de una entrevista aplicada antes de los siguientes instrumentos de evaluación psicológica: (a) Inventario de los signos y síntomas de estrés Lipp (ISSL), para evaluar el estrés; (b) Escalas de BECK de Ansiedad y Depresión (BAI y BDI), para evaluar la ansiedad y la depresión; (c) Escala Modos de Afrontamiento de Problemas (EMEP), para evaluar las estrategias de afrontamiento delante el estrés y (d) Entrevista individual preparada para la investigación. Las entrevistas fueran analizadas por la metodología de Bardin. Indicadores de estrés, ansiedad y depresión se encontraron en todas ellas, la práctica de pica más reportada fue pagofagia $(30,8 \%)$ y las frutas con sal (30,8\%). Las participantes reportaron un sentido de satisfacción después de la práctica. Teniendo en cuenta las asociaciones entre los trastornos alimentarios y desenlaces desfavorables, se considera importante investigar la Pica con el fin de proponer un cuidado prenatal más eficaz para la mejora de la salud de la díada madre-hijo.

Palavras clave: Embarazo, diabetes mellitus, Pica, ansiedad, depresión, afrontamiento.

Pregnancy is a moment of great expectations and changes in woman lives, and it is usually characterized by an emotional state of insecurity, fears and anguish (Sarmento \& Setúbal, 2003). This period is more critical when occurs under clinical conditions, as fetal or maternal risks like the Gestational Diabetes Mellitus
$(\mathrm{GDM})^{2}$. Among the different types of pregnancy risks, the GDM can result on significant

2 The Brazilian Society of Diabetes (SBD, 2015) defines GDM as any glucose intolerance of variable magnitude, that starts or is diagnosed in pregnancy. The DMG causes a decrease in the 
stress $^{3}$, and affect pregnant women and her fetus who are more vulnerable to physical (fetal death, macrosomia) and psychological problems (stress, anxiety and depression; Silva, Santos, \& Parada, 2004). These risks may cause an experience of psychological suffering for pregnants due to a significant impact of this diagnosis (Araújo, Pessoa, Damasceno, \& Zanetti, 2013). In addition, omen with GDM are more vulnerable to show depression (Nicklas et al., 2013) and anxiety (Morrison, Lowe, \& Collins, 2014) symptoms; as well as to develop type 2 diabetes at the postpartum (Morrison et al., 2014; Nolan, McCrone, \& Chertok, 2011). All of this results in unfavorable conditions for the development of mother-infant dyad, affecting the emotional bond between the woman, her baby and family (Quevedo, Lopes, \& Lefevre, 2006; Silva et al., 2004).

Sometimes woman adopts inappropriate and little resilient strategies to cope with these stressful conditions, and the eating disorders can appear during pregnancy in order to deal with the emotional instability (Ayeta, Cunha, Hendelman, \& Saunders, 2015). According to Dunker, Alvarenga e Alves (2009), these eating disorders are associated with metabolic, endocrine, psychological and nutritional changes, that result in negative effects for woman and her fetus, including high prevalence of abortions, low birth weight, obstetric complications and postpartum depression (Dunker, Alvarenga, \& Alves, 2009).

In this context, it is observed an eating disorder called Pica, that means an eating of one

sensitivity to insulin. Pregnant woman becomes vulnerable to fetal compromise (fetal macrosomia, fetal growth incompatible with gestational age due to maternal hyperglycemia. It results on a greater chance of fetal complications (neonatal hypoglycemia, respiratory disorders and even fetal death intrauterine; SBD, 2015; Brazilian Society of Endocrinology and Metabolism, 2015).

3 Stress can be defined as any reaction of the body, along with the psychological, physical, mental and hormonal components that occurs regarding the need for a great adaptation to a stressor, but that will be adverse if exposed for a long time or when there is a predisposition to certain diseases (Lipp, 2000, p. 109). or more non-nutritive or nonfood substances on a persistent basis over a period of at least one month, and it is severe enough to demand clinical attention (American Psychiatric Association, 2013). This disorder has been little studied, especially in regard to psychological aspects (Ayeta et al., 2015; Saunders et al., 2009, p. 441). According to the DSM-5, a person who be diagnosed with pica must show: (a) Persistent eating of non-nutritive substances for at least one month, (b) The eating of non-nutritive substances is inappropriate to the individual developmental level; (c) The eating behavior is not a part of a culturally or socially normative practice; (d) If the eating behavior occurs in the context of another mental disorder (e.g., intellectual disability, autism spectrum disorder, schizophrenia) or medical condition (including pregnancy), it is severe sufficient to demand additional clinical attention.

Rare studies indicate that this disorder is a practice culturally accepted in the pregnancy for different historical and cultural contexts (Kachani \& Cordás, 2009; Thihalolipavan, Candalla, \& Ehrlich, 2013; Young, 2010). Pica can occur even among the most privileged social classes of pregnant women (Mikkelsen, Andersen, \& Olsen, 2006). Literature has confirmed that the pica practice is a compensation of low levels of iron and/or a relief of specific pregnancy symptoms, such as morning sickness, nausea and edem (Ahmed, Abdullahi, \& Adam, 2012). Also, it has been transmitted as a transgenerational belief within the family (Kachani \& Cordás, 2009).

Studies suggest that there are important emotional aspects associated with pica, and this disorder is most often studied in pregnant women because of the risks to baby (Ahmed et al., 2012; Simpson, Mull, Longley, \& East, 2000; Thihalolipavan et al., 2013). Inappropriate substances consumed, often toxic (eg. talc, cigarette ashes, chalk, soap), may be associated with elevated blood pressure. Moreover, it can overcome the placental barrier reaching the fetus and causing premature birth, perinatal mortality, low birth weight, decreased brain perimeter and even abortion (Thihalolipavan et al., 2013). Pica can 
commit children's cognitive and communication development in a long term (Erdem, Hernandez, Kyono, Chan-Nishina, \& Iwaishi, 2004).

Due to the severe obstetric outcomes related to this practice during pregnancy, the diagnosis and treatment of this disorder are essential, especially because its cause and treatment are still controversial (Bhatia \& Kaur, 2014; Fiestas-Teque, 2014). On rare studies, it is consensus that pica is associated with stress during pregnancy, mainly to increase maternal stress in the 1st quarter of pregnancy, when the women need to be involved in a greater controlling diet that would cause anxiety and irritability. On this pregnancy moment, the intake of non-nutritious foods (pica) is a way to relief anxiety and stress (Kachani \& Cordás, 2009; Young, 2010). According to Young (2010), pica can be considered as an individual response of protection against the psychological distress, likes a "stress mediator" which acts on the immune system. However, this hypothesis is ambiguous and the author believes that it is necessary to conduct further studies with methodological rigor and longitudinal design in order to confirm this hypothesis and to clarify the relations between pica and pregnancy (Young, 2010).

Although the etiology of pica is complex and multifactorial, it has been suggested an association between emotional factors and pica practice, and relations between hormonal changes and distress are discussed. The increasing on synthesis of female hormones could causes mother's body changes and affects the fetal development (Vieira \& Parizotto, 2013). These hormonal changes may cause significant physical and psychological changes in women, and result in depressive symptoms, anxiety, poor concentration, irritability, changes in appetite, insomnia, hypersomnia and loss of energy (Vieira \& Parizoto, 2013; Simpson et al., 2000).

Some of these emotional conditions, such as anxiety, are present throughout pregnant-puerperal cycle, and sometimes they cause dissatisfaction, unrest, insecurity, doubts and fears. All of them updates the anguish and features anxiety changes during gestation (Sarmento \& Setúbal,
2003). Considering the emotional vulnerability during pregnancy, the typical emotional state of this period can result in stress and affect the coping process $^{4}$. In order to face with stress, pregnants can adopt dysfunctional coping strategies ${ }^{3}$ whose affect the development of mother-baby bond, like pica practice.

However, this hypothesis needs to be further investigated in specific contexts of vulnerability, such as the risk pregnancy with GDM and especially in national studies. Recent study discusses the relationship between pregnancy with GDM and pica in Brazilian pregnant women (Ayeta et al., 2015). Few studies have investigated associations between pregnancy with GDM and pica practice. Some of them confirms that the diabetes in pregnancy increases a high chance of developing this disorder (Ayeta et al., 2015; Ezzeddin, Zavoshy, Noroozi, Jahanihashemi, \& Riseh, 2015; Gangopadhyay, Karoshi, $\&$ Keith, 2011). Nevertheless, only one of these studies discussed psychological aspects related to pica in Brazilian pregnant women (Ayeta et al., 2015).

Pica is a disorder with difficult diagnosis and arduous notification because of the embarrassment that pregnants can experience due shame and fear associated with this practice (Kachani \& Cordás, 2009; Saunders et al., 2009). In a prospective study with 227 pregnant women from Maternidade Escola da Universidade Federal do Rio de Janeiro, same place that was conducted our study, Saunders et al. (2009) observed that this disorder was reported by $14.4 \%$ of women during the period from 2005 to 2006 and $42.1 \%$ women practiced everyday.

Finally, considering the multifactorial character, the difficulty of determining causes of pica and its association with negative obstetric outcomes, the prognosis of this disorder should be as favorable as the diagnoses and treatment are

4 It is considered a coping response as an intentional, physical or mental action, initiated in response to a perceived stressor, directed to external circumstances or internal states (fear, anxiety; Lazarus \& Folkman, 1984). 
early and based on an interdisciplinary approach, including doctors, psychologists and nutritionists (Kachani \& Cordás, 2009). Considering this discussion and the insignificant literature about pica, our objective was to analyze emotional indicators (signs of stress, anxiety and depression) and coping strategies of pregnant women with GDM and their reports of pica practice in her current pregnancy, seeking to discuss about possible links between these indicators and the pica practice, and how these associations may explain the desire of women for inadequate substances during pregnancy.

\section{Methods}

The study was based on an exploratory descriptive design and conducted with a convenience sample of 07 pregnant women, all of them were adults who were attended at the prenatal care service of Maternity School Hospital of Universidade Federal do Rio de Janeiro. All of them were diagnosed with Gestational Diabetes Mellitus (GDM) using the clinical protocol of institution (Bornia, Costa, \& Amim, 2013; International Association of Diabetes and Pregnancy Study Groups Consensus Panel [IADPSG], 2010). Also, they were diagnosed with pica using a standardized interview which was applied by nutritionist. This interview included questions about the occurrence and the frequency of pica, and the investigation about ingested substances.

Afterwards, the participants were scheduled for a psychological evaluation and individual interviews. Before that, the participants were informed about the research objectives and signed the Term of Free Consent approved by the Ethics Committee of the institution (CAEE n. 06386412.1.0000.5275 - 06\09\2013). Data collection and psychological evaluation of stress, anxiety, depression and coping occurred at the room of psychological care service.

The stress evaluation was made using the Inventory of Signs and Symptoms of Stress of Lipp (ISSL). This is a Brazilian psychometric scale to evaluate signs and symptoms of stress in different categories: physical, psychological or mixed. It also classifies the stress in 4 different phases:

1. Alarm, considered the positive phase of stress, it's related to the survival response

2. Resistance, the person tries to maintain an internal homeostasis, and there is more emotional distress, physical symptomatology and psychosocial manifestations,

3. Almost-exhaustion, it is characterized by weakening and difficulty to adjust and resist the situation, the person has great fatigue but she is able to execute some tasks

4. Exhaustion, considered the pathological stage of stress, it is characterized by the permanence of stressful stimulus that result in failures on the adaptive capacity of body with important inner imbalance, occurrence of depression and none productivity.

The evaluation of signs and symptoms of anxiety and depression was conducted using Beck Anxiety Inventory (BAI) and Beck Depression Inventory (BDI), based on the Brazilian psychometric and standard properties (Cunha, 2001). Each inventory is a 21 items self-report scale. The items represent common symptoms of anxiety (BAI) and depression (BDI) that person has had during the past week, including the day of application. The scoring is based on a 0-3-point scale for each item and the interpretation of scores is based on a total sum of those items.

1. For anxiety: (a) minimal $=01$ a 07 ; (b) mild $=08$ a 15 ; (c) moderate: 16 a 25 ; e (d) severe: 26 a 63 ; and

2. For depression: (a) minimal: 01 a 09; (b) mild $=10$ a 16 ; (c) moderate: 17 a 29; and (d) severe: 30 a 63 .

Considering the context of risk pregnancy, the participants also responded the Ways of Coping Scale - EMEP (Seidl, Tróccoli, \& Zannon, 2001). The EMEP is a Brazilian scale that allows a clinical and qualitative analyses of coping strategies. The EMEP has 45 items, divided into factors, that classify coping in four types: (a) problem-focused coping; (b) emotion-focused coping; (c) coping based on religious practice 
or imaginative thoughts; (d) coping based on the search for social support. The scoring is based on a Likert scale: $1=\mathrm{I}$ never do it; $2=\mathrm{I}$ do that a little; $3=\mathrm{I}$ do it sometimes; $4=\mathrm{I}$ do it a lot; $5=\mathrm{I}$ always do it. The coping description results from an average of those factors. The EMEP scale has a consistent factor structure based on the literature about coping (Seidl et al., 2001).

The BDI was applied at the day of the interview in order to examine more relations between depression and pica practice. Due to the inability to schedule an interview with one women before her delivery, only six participants were interviewed and evaluated with BDI. For the interviews it was used a semi-structured script with nine questions. This script was made especially for this study in order to collect the verbal report of pregnants about their experience related to GDM and pica practice. The aim of the interview was to understand how this eating disorder appears during pregnancy, as well as how to explain the woman's desire for consuming unusual food combinations or bizarre substances and its relationships with stress, anxiety, depression and coping. The interviews were conducted individually, all were recorded, transcribed, and analyzed based on the content analysis methodology of Bardin (1977/2006).
Data from the interviews were analyzed descriptively and qualitatively, based on the analysis of pregnants reports and the frequency of occurrence of following macro-categories: (a) "Motivation to pica practice"; (b) "Personal history of pica practice"; (c) "Desire satisfaction"; (d) "Satisfaction in intake"; (e) "Desire Sharing"; (f) "Family support". The data of the inventories (BAI, BDI, ISSL and EMEP) were analyzed according to the standards procedures of each instrument.

\section{Results}

Most of participants $(61.52 \%)$ had high school and $85.8 \%(n=06)$ of them exercised any paid work (manicure, homecare, office assistant, nursing technician, among others). Most of them $(85.8 \%)$ had a partner $(n=6)$ and children $(n=$ $6)$. Related to the religion, $85.8 \%$ of them declared to be Christian (Protestant, mostly) and $14.2 \%$ Spiritist, practitioners or not.

Anxiety data identified by BAI are shown in Figure 1. It can be observed that no pregnant women showed signs of severe anxiety. Furthermore, $71.4 \%(n=06)$ were classified as moderate level of anxiety; while $28.6 \%(N=02)$ had mild level.

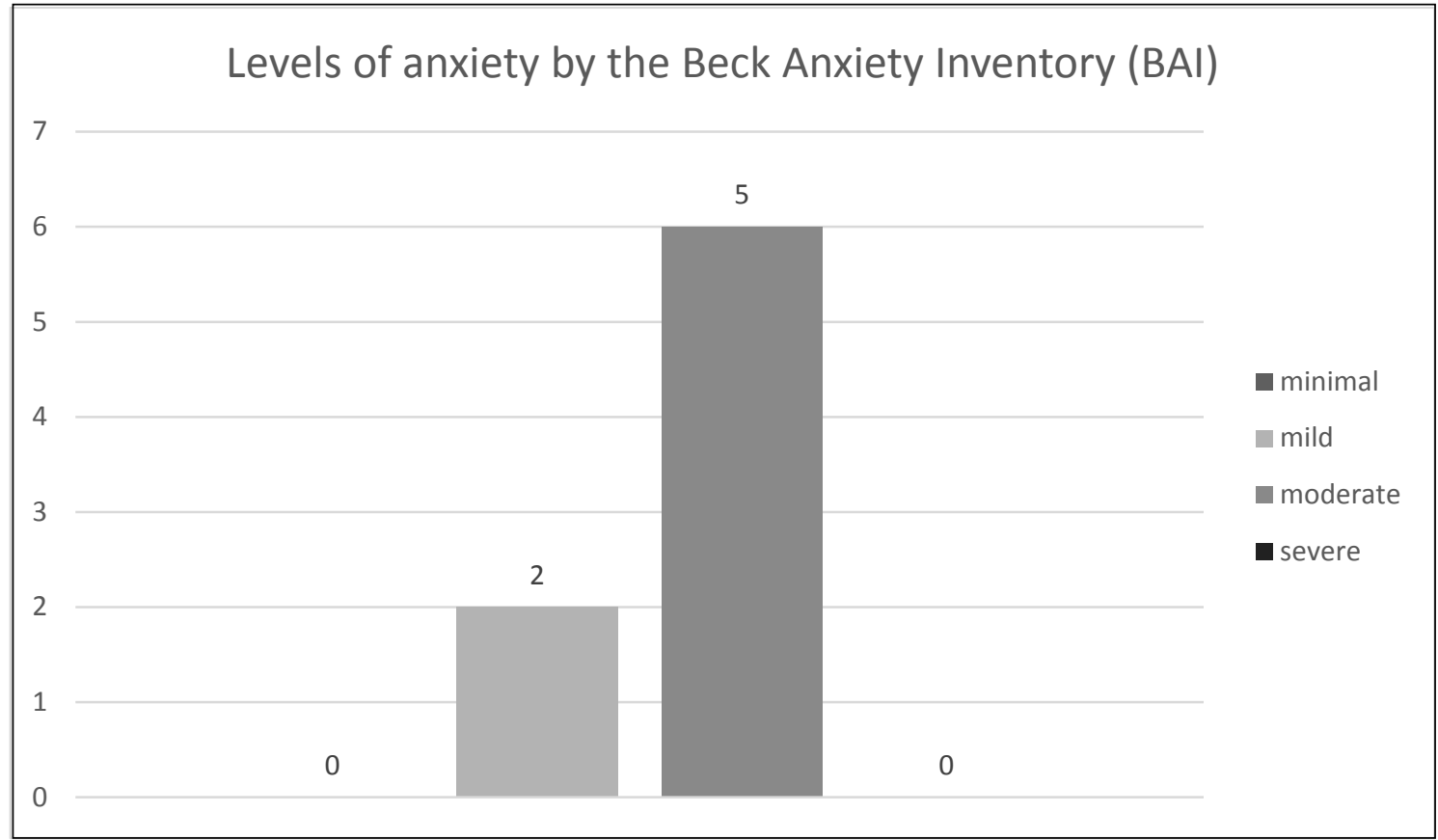

Figure 1. Anxiety levels by Beck Anxiety Inventory - BAI (N = 07). 
Regarding to depression, the data obtained by BDI are shown in Figure 2. All pregnant women had some degree of depression, including four pregnants with moderate depression (66.6\%), one with severe depression (16.6\%), and only one with mild depression symptoms $(16.6 \%)$.
Figure 3 shows the results of stress evaluated by ISSL. It can be observed that five women $(71.4 \%)$ were in the resistance phase, two (28.6\%) were in the exhaust phase; while no pregnant woman showed any signs and symptoms of stress in phases 1 (alarm) and phase 3 (almost-exhaustion) of stress.

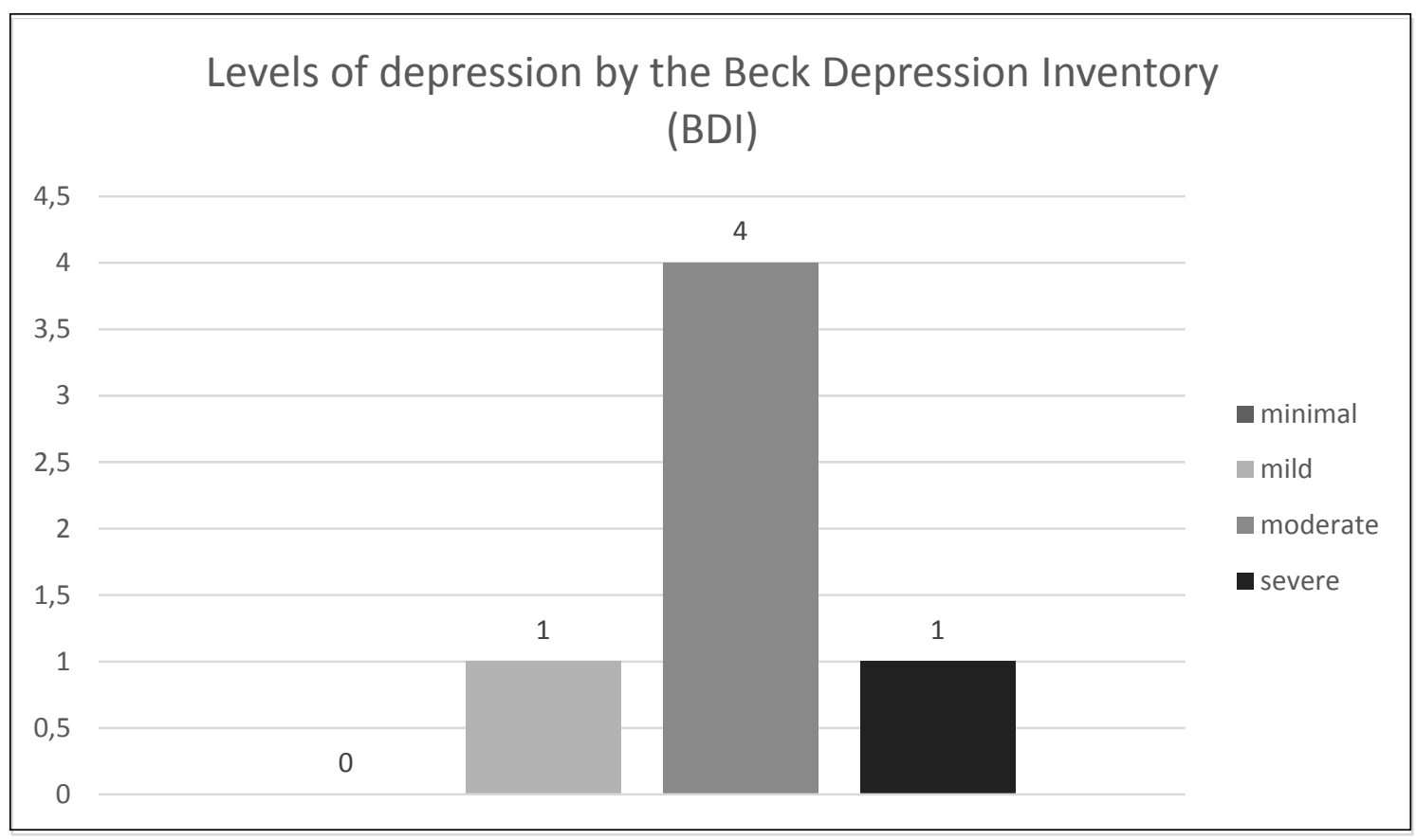

Figure 2. Depression levels by Beck Depression Inventory - BDI (N=7).

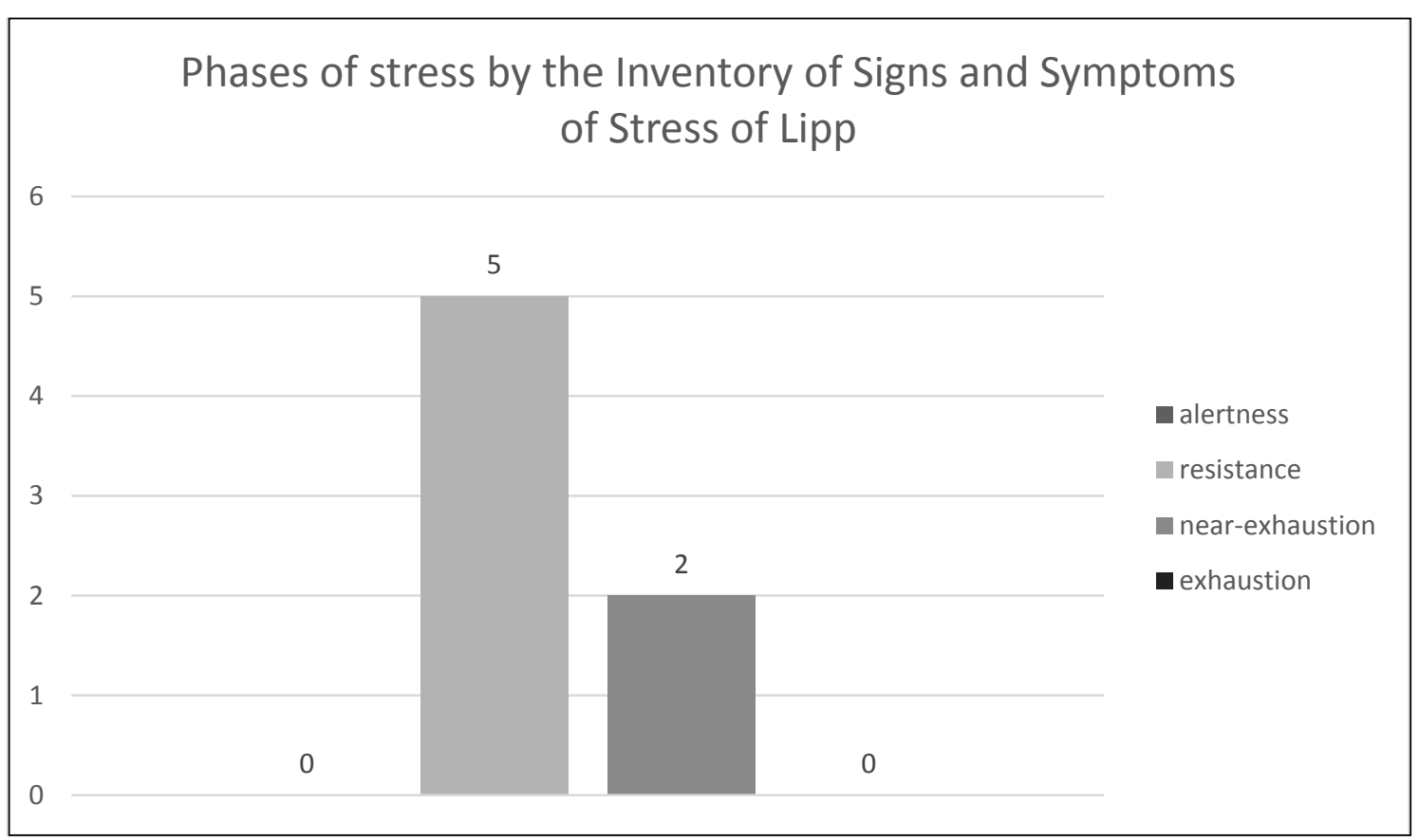

Figure 3. Phases of stress by Inventory of signs and symptoms of stress of Lipp - ISSL (N=07) 
Table 1

Frequency of Pregnant Women by Most Prevalent Type of Coping, according to EMEP, Ways of Coping Scale $(\mathbf{N}=\mathbf{0 7})$

\begin{tabular}{ccc}
\hline Classification in EMEP & Frequency & Percentile \\
\hline Coping based on religious practice or imaginative thoughts & 03 & 42,8 \\
Coping based on the searching for social support. & 03 & 42,8 \\
Problem-focused coping & 01 & 14,4 \\
Emotion-focused coping & 0 & 0 \\
\hline Total & 07 & 100,0 \\
\hline
\end{tabular}

On Table 1 can be analyzed the prevalence of coping used by pregnant women identified by the Ways of Coping Scale - EMEP.

According to the evaluation of coping by EMEP, no participant used emotion-focused coping. We can observe that $42.8 \%$ of pregnant women used the coping based on religious practice or imaginative thoughts as more prevalent strategy. Also, three other participants (42.3\%) used the coping based on the search for social support, while only one woman used coping based on problem-focused.

On the verbal report of pregnants we identified some themes that were more frequent than others during the interviews. These themes were analyzed in those macro-categories described before, and their results will be presented descriptively and quali-quantitatively. It is important to highlight that the combination of foods most frequently cited by participants were fruits with salt, such as green mango, pineapple, hog plum and lemon with salt, identified as a pica practice according to the diagnostic criteria. However, there were also women reports about consuming of exotic combinations, such as peanut brittle with bread, and not appropriated substances for consumption, such as detergent and Phebo soap.

Regarding to the "Motivation to pica practice", despite the fact of participants had reported that their desires for consuming exceeded the recommended diet, it was observed that all women shared the belief about a "desire satisfaction", as this report suggests:

I sat down and ate a full bowl, with a great desire. It was delicious! . . The mango and the sugar made me neglect the diet. Because in the mango [phase] I had high blood pressure, and in the other I was diabetic and couldn't eat sugar. I had to use a sweetener, but then I stopped, I had no more (to use a sweetener) control to diabetes. (G3)

In some cases, this desire for consuming was focused even on the intake of inappropriate substances or exotic and unusual combinations, which could compromise the health of mother and baby, such as "suck naphthalene".

When asked about the motivation to the desire, $75 \%$ reported the smell of food or products as the stimulus for their desire, such as this report:

I could not go to the bathroom and see the soap because I wanted to eat, I rubbed it well in the tongue, and then I got sick because the taste was not like the smell, and what attracted me was the smell... and you're salivating, salivating when you see that the taste is not like the smell. (G4)

One participant reported her feelings related to the desire for consuming talking about the substance during the interview. At that moment, she felt the desire: "It makes me want to eat it. Like the smell of coconut that I'm feeling now. I quickly remember detergent because it has this smell and then it makes me want to eat, to take the detergent" $(\mathrm{G} 2)$.

The theme "Personal history of pica practice" appeared during interviews when participants talked about a peculiar desire for exotic combinations. Fruits with salt were cited by some pregnant women. Also, desires that were already part of their routine increased frequency during pregnancy. One of pregnant even reports 
that her consumption of lemon with salt was shared by the family:

It's common. Yes. My mother did not, but my brother did. It was a kid stuff. It was like this, we [used to] bought lemon to make use of them [for pica], and then we [used to] just put salt on it. (G1)

However, the desire for inadequate substances has been reported as a behavior initiated during pregnancy. Some participants further reported that they experienced exotic desires and practiced pica since her first pregnancy. It was also observed that eating exotic food combinations and the desire for inappropriate substances were perceived as strange feelings by these women, as well as a great demand satisfaction. "I was hesitant for a little while, if it is a very strange thing, but it comes in a time that is difficult, because the will is too big, you really spittle" (G4). Most of pregnant reported that the desire for exotic combinations and lor inappropriate substances disappeared after the end of pregnancy.

According to the reports it was possible to perceive that it is a "desire satisfaction". There was a kind of pleasure involved on the pica practice, as illustrated by the following report: "Because the will is too large, you spittle a lot. I really wanted to eat hog plum. Only by talking my mouth already spittle. But it has to be with salt, because it doesn't' work pure" (G4). The fulfillment of desire was showed as a something emphatic in every interview, and it was recognized as a something that consumes them and needs to be immediately satisfied by women. In this way, pregnants reported that the desire assumed a subjective representation characterized as an overwhelming experience that appears suddenly and sometimes uncontrollably, like this example: "This is the desire. You eat so much and extrapolate" (G3). "The desire is sudden and comes at any time" (G4).

All pregnant women said that they felt an uncontrollable desire, which controls her thoughts until to be satisfied. It can be curbed only when there is an awareness that can harm their health and the baby health. It is very serious if we discuss the case of a woman who had a desire for naphthalene, and she consumed it even after the doctor warned her about damages for her health and the baby. The report below shows how overwhelming desire can be present in pica, when the practice was only controlled by the awareness of warning:

I try to control myself. I tried to control and manage as far as possible, but tried not to keep that desire. Same as naphthalene, I talked to doctor and she said that it was bad, so I stopped. I wanted, but I didn't eat. . . . Same as naphthalene, I don't know how long passed, then it returned. One day I managed not sucking it when I felt a very strong smell in my friend's house. Because I know it's bad. It's not something that you cannot control. (G2)

Most of participants reported that their experience of fulfillment of desire results on the "mouth watered" sensation. This sensation expresses the desire itself. Regarding to this, the frequency of ingestion of these foods varied per each pregnant woman: it could be weekly or daily. Some of them said that her consuming is every day $(25 \%)$, or only when they were in specific places $(50 \%)$, as the family home or at work. Others pregnants reported that they consumed only when they were alone (25\%). It was observed a story about an extreme case of consuming of exotic combination (pineapple with salt) for three days:

I had three days in a row only pineapple with salt, without any food, only pineapple with salt. I even lost weight and doctor censured me. I did not drink coffee, eat anything, it was only pineapple with salt. I drank water normally, but not food, I only wished to eat pineapple with salt. (G4)

The location and the way of consuming of inappropriate substances or exotic combinations were unique for each woman. While one participant reported that she practiced pica even at her workplace, another one reported that she practiced it when hidden. About this last woman, when she was asked about the reason for consuming in thus way, she said: "I hid because of my pressure problems, this is the reason why I did not tell anyone". And she completed: "it was 
my secret" (G3). Two women also reported their consuming in front of their families, even when they complained, and highlighted the fact of pica could harm their pregnancy development.

Related to the theme "Satisfaction in intake", women reported that she shared a feeling of satisfaction related to pica practice. They highlighted the sensation of "the desire satisfaction" that results on "a relief sensation". However, they also showed concerns about their health and their baby health. Some of them declared guilty feelings, such as: "It generated a guilt, because of it I knew that the exam would be altered" (G1), reporting the abusive consumption of sugar. Also, there was a concern about the consequences of pica. "After... I was afraid of the pressure. It made me worried. Sometimes I said when the will came: I can't, I can't, because eating this will affects my health and her [baby's] health" (G3).

About the category "Sharing the desire", it was observed an interesting fact that appeared in some reports. It was evident that the feeling of shame was not showed during the interviews when pregnants were talking about their desire. Women reported on an strange feeling related to these desires, but it was not necessarily resulted on a limitation talking about them. Sometimes they were seeking to share this experience with other women to find similarities in their behaviors and feeding habits, and to feel a positive or negative identification with their peers, as this example:

An acquaintance of mine who is pregnant, who is my husband cousin. She's pregnant and diabetic as well. But she's addicted. And I met her in my mother house where I was eating, then she saw and asked me to pick up a green mango for her, too. (G2)

Finally, the theme "Family support" was showed an important aspect related to the involvement of pregnant women in her health and mother-infant dyad. The presence of family members in this period seemed to guarantee the woman doesn't feel alone or helpless:

The first time I sucked 5 lemons, because the day after I would have to take an exam. My mother argued me and [then] I didn't suck any more. My mouth began to burst here, began to crack, so I stopped because it was burning a lot. (G2)

"And my husband said: For God sake! Not the disinfectant! If I go somewhere and feel the smell I want to take it" (G4 referring to the consumption of disinfectant).

\section{Discussion}

Pregnant women who practice pica show significant signs of stress at some level (Ayeta et al., 2015; Woods, Melville, Guo, Fan, \& Gavin, 2010), and many of them develop signs of anxiety during pregnancy (Vythilingum, 2008). Psychological variables, such as anxiety and depression, can affect the mother during prenatal period, contributing to negative obstetric outcomes, such as prematurity, low birth weight and child development problems (Ding et al., 2014; Van Batenburg-Eddes et al., 2013). Maternal stress may also be related to negative emotional outcomes (Davis \& Sandman, 2010; Rodrigues \& Schiavo, 2011; Woods et al., 2010). These emotional conditions can be intensified in a risk pregnancy, such as pregnancy with pica and GDM. It's important to investigate the relationship between these risks and the coping strategies.

There is few literature that discuss relations among pica, GDM and psychological factors, such as anxiety, stress, depression and coping strategies (Araújo et al., 2013; Ayeta et al., 2014; Morrison et al., 2014; Nicklas et al., 2013; Nolan et al., 2011; Silva et al., 2004). Our results suggest that the diagnosis of GDM can be related with anxiety, depression and stress in pregnant women. It requires the adoption of resilient coping strategies in order to prevent eating disorders, like pica. Also, resilient coping strategies are the best way to protect women from psychological distress.

As previous study suggested (Ayeta et al., 2015), it was observed a prevalence of two types of coping among pregnants with pica: "coping based on the searching for social support" and "coping based on the religious practice or imaginative thoughts". Regarding to the "coping 
based on the searching for social support" we observed that family support was very important for most of those women, either because they share the same food preferences, or because family members prevent the fulfillment of uncontrolled desire for substances, sometimes toxic (detergents, for example) or exotic (mango with salt, lemon with salt, etc.). In fact, the social support plays an important role related to risk pregnancy, because family becomes the main support for women with pregnancy complications. In the context of risk pregnancy, the family usually promotes a satisfactory evolution of risk pregnancy, including the family adaptation to medical recommendations, and the adherence to treatment of disease (Petroni, Silva, Santos, Marcon, \& Mathias, 2012).

Coping based on religious practice or imaginative thoughts was also the second most prevalent coping strategy among participants in study of Ayeta et al. (2015). This coping was observed on the interviews of our study when women reported her worries about "disastrous consequences" for baby as a motivation to avoid the fulfillment of pica desire. The report of a pregnant woman about her mother's pregnancy and her own birth can illustrate this:

I was born with ruffled hair because she wanted to eat a chicken with okra and my grandmother didn't do it and I was born like that [a chicken]. You had to see my pictures when I was small with ruffled hair. That's ridiculous! I said: "Why not shaved the head of this child?".

Beliefs and superstitions, represented by imaginative thoughts, is the main feature of "coping based on religious practice or imaginative thoughts". On the report above there are some examples that explain this kind of coping strategy. Furthermore, it is common that women have a unique psychological, physical and social experience during pregnancy, which results on an elaboration of different expectations about the baby and the maternity. Particularly, distressing fantasies about the fetus integrity (Soulé, 1992) can transform the pregnancy into a stressful psychological experience that elicits emotional crises (Sarmento \& Setúbal, 2003). Women can use this coping strategy to deal with this context, as illustrated on the following report: ". . . A colleague of mine said that this is psychological, that is missing something in the baby, and sends a message to my brain in a brick form, and I said: it's a house under construction". Concomitant to this, we cannot forget that the literature has highlighted cultural aspects of pica practice. Sometimes pregnant also believes that she must ingest inappropriate or exotic substances in order to the baby born healthy and perfect (FiestasTeque, 2014; Young, 2010).

Additionally, it is important to consider associations among risk factors, such as GDM, pica, and coping strategies related to the stress and anxiety characteristic of pregnancy period. Regarding to the coping, it was also observed on the interviews that women described different meanings related to their overwhelming desire for consuming unusual foods or toxic substances. We could even affirm that this attitude might seem an attempt to excuse their uncontrollable act, as in the case of woman who consumed naphtalene. It is important to highlight that this women had information about the immediate causes and direct consequences of their eating disorder for their pregnancy. This knowledge was acquired with the doctor and the nutritionist.

On the other hand, some participants had a family tradition of eating unusual combinations of no nutritional foods, like lemon with salt. So, this consuming behavior was a familiar tradition that was perpetuated as a habit and justified by a strong transgenerational belief (Ahmed et al., 2012; Kachani \& Cordás, 2009; Thihalolipavan et al., 2013; Young, 2010). This fact seems to justify the pica practice between those pregnant women, that was had been presented since early pregnancies. We can observed on the women reports about their history of pica practices that the desire and the practice itself were already part of familiar routine, which increased during that pregnancy.

The pica practice can also be seen as a way to relief the stress, anxiety and depression related to the risk pregnancy, as suggest the literature (Ayeta et al., 2015; Kachani \& Cordás, 2009; Young, 2010). In our study, all women showed 
some type of emotional factor in different levels, which is important to be discussed. All of them showed symptoms of stress and anxiety, that means the women were in a resistance stress phase characterized by the searching for homeostasis. The misbalance created by the persistence of stress can cause a susceptibility for some pathologic symptoms (Lipp, 2000).

The presence of stress and its relation with anxiety highlights the importance of studying the pica as a "stress mediator", especially if we consider pregnancy as a period of significant emotional repercussions for women (Sarmento $\&$ Setúbal, 2003). We can affirm that, not forgetting the limitations of data generalization, symptoms of stress and anxiety are common in cases of pica, as confirmed by previous study (Ayeta et al., 2015). Additionally, we can affirm that these psychological manifestations are a way to unburden, as much as possible, all tension created by internal or external events. This tension requires to women rebalances herself for attending specific demands, such as the GDM. As McDougall (2003) highlights, the tension can be related to painful affective states or to a pleasant affective states, both can cause great excitement and euphoria, and be perceived and interpreted as a prohibited or dangerous situation. This statement could explain the pica related to an experience of psychological ambivalence for those women, because they reported great satisfaction and pleasure for that consuming, as well as guilt and worries related to harming their health and their baby health.

Pica may be related to anxiety, present since the first quarter of pregnancy and related to the necessity for greater diet control. This control can be stressful for pregnant and her family, resulting on irritability caused for typical hormonal changes during pregnancy (Vieira \& Parizoto, 2013). Also, in some interviews it was observed that they stopped the consumption of strange combinations of food, toxic or inappropriate substances only after the second trimester. This suggests that pica can be represent a way to relieve anxiety and stress (Kachani \& Cordás, 2009; Young, 2010), especially at the beginning of pregnancy when diet control is more severe particularly in the GDM (Ayeta et al., 2015).

We can also draw attention to the fact of all participants had some degree of depression, with most moderate symptoms of depression and even severe symptoms in one participant. These data should be discussed carefully, because depression is an important disorder that can affect the women before and after child-birth, resulting on postpartum depression and postpartum psychosis. We can assume that these symptoms of depression are important to be more widely investigated. This investigation must consider the individual experience related to the changes and demands of pregnancy, that results on a unique coping way of each woman. It can explain why pica is a disorder presents in some pregnancy but not in others. Thus, it is essential understand the history of each woman as an expression of worries about their own pregnancy, when physical and psychological changes and their symbolic effects may result in fear, anguish, anxiety, depression, malaise and sometimes somatizations of something that cannot be expressed in words. On the other hand, in intra-group analysis it was possible observe that pregnants with moderate depression symptoms also had a chronic disease in addition to GDM, such as high blood pressure for example. This chronic condition also results on psychological risk factor for the women mental health. According to Quevedo et al. (2006), sometimes pregnant woman with a high-risk condition presents difficulties for an emotional adjustment, that is required for women when she became mother. This new social and psychological role results in a necessity to deal with different demands and many others emotions. Also, the women feel a real fear due to pregnancy risks, that increases face to worries related to their own body and to their child (fear of abnormalities, for example). All this requires a special attention to the emotional health of these women, because it may indicate or increase depressive symptoms, like our findings.

It is important to highlight that was observed in our study pregnant with symptoms of severe depression, and stress in exhaustion phase, who 
used a coping based on problem-focused. This can reflect different risk factors (for pregnant health and her baby) related to an emergence of depressive symptoms. Despite of the fact that coping based on problem-focused is considered as a resolute and adaptive strategy to deal with stress situations, a preventive care is essential in these cases. This coping doesn't assure a resilient coping for preventing depression because of it tends to be used in unchangeable situations (Folkman \& Lazarus, 1980), that not occur in our study. In our study, all woman has GDM and must to deal with a gestational risk during the entire journey of pregnancy. GDM is not a reversal situation, and those women can only manage not change this clinical condition. On the other side, the coping based on problem-focused could induce the woman adopts rationalization strategies for searching information and alternatives to deal with the problem (Lazarus \& Folkman, 1984). It also allows women use resolute mechanisms to cope with their vulnerable condition, and to prevent risks related to depressive symptoms, for example.

Saunders et al. (2009) affirm that the pica can be an adaptive behavior, crossed by the acceptance and the representation of a physiological need or a desire of pregnant woman for nonnutritive substances. The authors affirm that the pregnancy experience can induce the women readapt face to changes life. On the same way, our study invites us to understand that there are psychological factors which explain the desire for inappropriate substances: pica. Similarities between behaviors and eating habits of women with pica can suggest that there is a social representation of pregnancy that legitimizes to woman an acceptance to fulfill inappropriate desires that are considered aggressive to health.

Different from the literature (Kachani \& Cordás, 2009), in our study it was not common the shame in sharing pica between participants and their family. However, the analyze of women reports can allow us to think about and reflect on how significant the desire satisfaction is. This desire can even represents an empowerment for pregnats because those women felt a kind of pleasure, relief, satisfaction and other adjectives used by them, such as: "Looks like I'm stuk on that ... I dont know! It's a strange thing" (G2 referring to the desire) and "I satisfied the desire and it was good because I did not put out" (G3 referring to the sensation after intaking green mango with salt). Despite the desire results on ambivalence (contentment and guilt), the participants continued performing their pica practice and negating their ambivalence of feelings, especially when they consumed toxic substances, such as soap, detergent, disinfectant, brick etc., like this example: "When these strange things are present... It is a little unhygienic, right?' (G4 referring to the consumption of Phebo soap).

Part of participants reported difficulties in performing their pica practice in front of their families. The family support may have helped them to face with adversities related to their life moment, especially considering that all respondents had GDM and significant symptoms of stress, anxiety and depression. Also, the family support perceived by pregnants may have helped to control their practice. Family members may have represented an interdiction which helps those women to deal with the urgency of fulfillment of pica desire. Some women reported that even if the family members didn't support the consumption of some substances, they were around her providing friendship and help, as this example: "Much. Everything that happens in my pregnancy, not only in this but in all, he is present. He comes and asks, he wants to know how is the baby. He was here with me now. . ." (G4, referring to her partner presence during pregnancy).

Reports about the family support confirm the idea that coping strategies of pregnant with pica are focused on the coping based on searching for social support (Ayeta et al., 2015). These women showed a minimum level of anxiety, which could indicate that family support influences the management of risk pregnancy. An adequate social support is essential during critical important moments present throughout the life, such as pregnancy, childbirth and postpartum period. On these periods, women are required to be 
proactive for a long and intense time. Therefore, social support offers environmental control and autonomy for women during pregnancy and puerperal period because it provides hope, support and protection to deal with difficult situations (Coutinho, Baptista, \& Morais, 2002). Moreover, this support is critical to promote the welfare, because, according to Petroni et al. (2012), the family can represent a positive way for reducing anxiety and transmitting confidence for women with high-risk pregnancy. Thus, social and family support are important factors which ensure maternal mental health and adaptive coping to face with vulnerable situations.

The pica at first pregnancy can be considered a repetitive behavior that facilitates a perpetuation of consuming exotic substances, because it is something known and easy to handle. Furthermore, the repetition of pica may be related to difficulties to control an intense desire or eating compulsion. Studies indicate that the pica may be related to serotonin receiving system, like an eating compulsion that involves the inhibition of an instinctive behavior (Bhatia $\&$ Kaur, 2014). This hypothesis could be tested in future studies that investigate the coping process related to self-regulation system of emotions and behaviors. It was not exactly the focus of our study, but it can be tested in further researches.

Finally, it should be emphasized that our data discussion has some limitations. The sample size limits the results generalization. The limitation of our sample difficult to exam statistical associations and correlations using quantitative data analysis in order to draw large conclusions. However, our findings can offer a contribution to the scientific literature about pica, that is very limited because the great difficulty of accessing the population diagnosed with pica (Ayeta et al., 2015; Kachani \& Cordás, 2009; Saunders et al., 2009). Summarizing, our findings represent an initial discussion based on our study objective: discussing relations between emotional indicators and coping, and also investigating the desires that permeates the pica practice in risk pregnancy with Gestational Diabetes Mellitus.

\section{Conclusion}

We can conclude that food choices should not be understood only based on technical and scientific rationality, but also as an expression of singular forms of each individual or group (Baião \& Deslandes, 2010). According to this, we could think that pica is a way to deal with the anguish and the insecurity experienced for women during the pregnancy. This subjective representation transcends the nutritional medical sense that is focused on eating habits. In this direction, our data confirm the necessity to care about the maternal mental health in this group to offer therapeutic services. These services must include a clinical differential diagnosis, and an effective therapeutic procedures to minimize the impact of pica on women, with or without chronic health conditions like GDM. We highlight the participation of psychologists in prenatal care in a multiprotection approach with different health professionals. The health care staff should be sensitized to care and assist these women with pica, identifying them and providing to them a comprehensive health care. However, in order to understand the reality of pregnant woman and to think about measures for preventing health risks, it is important further studies focusing the mother-infant dyad. These studies should be planning on longitudinal design with objective to investigate associations among pregnancy risks, chronic health conditions, peculiar behaviors and emotional indicators (depression, stress and anxiety). Future researches on women's experience related to all problems during the pregnancy and postpartum period would improve the discussion about psychological aspects present after childbirth, like postpartum depression for example. Frequently under-diagnosed, the depression is a common psychopathology of that period, especially in women with eating disorders, and can be related to the way of woman to deal with typical stress related to the childbirth and her motherhood experience. 


\section{References}

Ahmed, S., Abdullahi, H., \& Adam. I. (2012). Practice of pica among pregnant women in Khartoum, Sudan. International Journal of Gynecology and Obstetrics 118, 71-76.

American Psychiatric Association. (2013). Diagnostic and statistical manual of mental disorders ( $5^{\text {th }}$ ed.). Arlington, VA: Author.

Araújo, M. F. M., Pessoa, S. M. F., Damasceno, M. M. C., \& Zanetti, M. L. (2013). Diabetes gestacional na perspectiva de mulheres gravidas hospitalizadas. Revista Brasileira de Enfermagem, 66(2), 222-227.

Ayeta, A. C. C., Cunha, A. C. B., Heidelmann, S. P., \& Saunders C. (2015). Fatores nutricionais e psicológicos associados com a ocorrência de picamalácia em gestantes. Revista Brasileira de Ginecologia e Obstetrícia, 37, 571-577.

Baião, M. R., \& Deslandes, S. F (2010). Práticas alimentares na gravidez: Um estudo com gestantes e puérperas de um complexo de favelas do Rio de Janeiro (RJ, Brasil). Ciência Saúde Coletiva, 15(Suppl. 2), 3199-3206. doi:10.1590/S141381232010000800025

Bardin, L. (2006). Análise de conteúdo (L. de A. Rego \& A. Pinheiro, Trans.). Lisboa: Edições 70. (Original work published 1977)

Bhatia, M. S., \& Kaur, N. (2014). Pagophagia - A common but rarely reported form of pica. Journal of Clinical \& Diagnostic Research, 8(1), 195-196.

Bornia, R. G., Costa, I. B., Jr., \& Amim, J., Jr. (2013). Protocolos Assistenciais. Maternidade Escola. Universidade Federal do Rio de Janeiro. Anestesiologia, Neonatologia, Obstetrícia. Retrieved from http://www.me.ufrj.br/portal/images/stories/pdfs/obstetricia/diabetes_mellitus.pdf

Brazilian Society of Diabetes. (2015). Diretrizes da Sociedade Brasileira de Diabetes. São Paulo, SP: Author.

Brazilian Society of Endocrinology and Metabolism. (2008). Diabetes mellitus gestacional. Revista da Associação Médica Brasileira, 54(6), 477480 .

Coutinho, D. S., Baptista, M. N., \& Morais, P. R. (2002). Depressão pós-parto: Prevalência e correlação com o suporte social. Infanto - Revista de Neuropsiquiatria da Infância e Adolescência, 10, 63-71.
Cunha, J. A. (2001). Manual da versão em Português das Escalas Beck (J. A. Cunha, Trans.). São Paulo, SP: Casa do Psicólogo.

Davis, E. P., \& Sandman, C. A. (2010). The timing of prenatal exposure to maternal cortisol and psychosocial stress is associated with human infant cognitive development. Child Development, 81(1), 131-148.

Ding, X., Wu, Y., Xu, S., Zhu, R., Jia, X., Zhang, S., ...Tao, F. (2014). Maternal anxiety during pregnancy and adverse birth outcomes: A systematic review and meta-analysis of prospective cohort studies. Journal of Affective Disorders, 159, 103-110.

Dunker, K. L. L., Alvarenga, M. S., \& Alves, V. P. O. (2009). Transtornos alimentares e gestação Uma revisão. Jornal Brasileiro de Psiquiatria, $58(1), 60-68$.

Erdem, G., Hernandez, X., Kyono, M., Chan-Nishina, C., \& Iwaishi, L. (2004). In-utero lead exposure after maternal ingestion of Mexican pottery: Inadequacy of the lead exposure questionnaire. Clinical Pediatrics, 43, 185.

Ezzeddin, N., Zavoshy, R., Noroozi, M., Jahanihashemi, H., \& Riseh, S. H. (2015). Prevalence and risk factors for pica during pregnancy in Tehran, Iran. Eating and Weight Disorder, 20, 457-463.

Fiestas-Teque, L. (2014). Pica en anemia severa: a propósito de un caso. Revista de NeuroPsiquiatría, 77(2), 123-125.

Gangopadhyay, R., Karoshi. M., \& Keith. L. (2011). Anemia and pregnancy: A link to maternal chronic diseases. International Journal of Gynecology \& Obstetrics, 115(1), 11-15.

International Association of Diabetes and Pregnancy Study Groups Consensus Panel. (2010). International association of diabetes and pregnancy study groups recommendations on the diagnosis and classification of hyperglycemia in pregnancy. Diabetes Care, 33(3), 676-682.

Kachani, A., \& Cordás, T. A. (2009). Da ópera-bufa ao caos nosológico: Pica. Revista de Psiquiatria Clinica, 36(4), 162-169.

Lazarus, R. S., \& Folkman, S. (1984). Stress, appraisal and coping. New York: Springer.

Lipp, M. E. N. (2000). Manual do inventário de sintomas de stress para adultos de Lipp (ISSL). São Paulo, SP: Casa do Psicólogo. 
Mcdougall, J. (2003). Théatre du corps. Paris: Folio essais.

Mikkelsen, T. B., Andersen, A. N., \& Olsen, S. F. (2006). Pica in pregnancy in a privileged population: Myth or reality. Acta Obstetricia et Gynecologica, 85, 1265-1266.

Morrison, M. K., Lowe, J. M., \& Collins, C. E. (2014). Australian women's experiences of living with gestational diabetes. Women and Birth, 27, 52-57.

Nicklas, J. M., Miller, L. J., Zera, C. A., Davis, R. B., Levkoff, S. E., \& Seely, E. W. (2013). Factors associated with depressive symptoms in the early postpartum period among women with recent gestational diabetes mellitus. Maternal and Child Health Journal, 17, 1665-1672.

Nolan, J. A., McCrone, S., \& Chertok, I. R. (2011). The maternal experience of having diabetes in pregnancy. Journal of the American Academy of Nurse Practitioners, 23(11), 611-618.

Petroni, L. M., Silva, T. C., Santos, A. L., Marcon, S. S., \& Mathias, T. A. F. (2012). Convivendo com a gestante de alto risco: A percepção do familiar. Ciência, Cuidado e Saúde, 11(3), 535-541.

Quevedo, M. P., Lopes, C. M. C., \& Lefevre, F. (2006). Os significados da maternidade para mulheres cardiopatas e diabéticas com gravidez de risco. Revista Brasileira Crescimento Desenvolvimento Humano, 16(1), 12-21.

Rodrigues, O. M. P. R., \& Schiavo, R. A. (2011). Stress na gestação e no puerpério: Uma correlação com a depressão pós-parto. Revista Brasileira de Ginecologia e Obstetrícia, 33(9), 252-257.

Sarmento, R., \& Setúbal, M. R. V. (2003). Abordagem psicológica em obstetrícia: Aspectos emocionais da gravidez, parto e puerpério. Revista Ciências Médicas, 12(3), 261-268.

Saunders, C., Padilha, P. C., Líbera, B. D., Nogueira, J. L., Oliveira. L. M., \& Astulla, A. (2009). Picamalácia: Epidemiologia e associação com complicações da gravidez. Revista Brasileira Ginecologia Obstetrícia, 31(9), 440-446.

Seidl, E. M. F., Tróccoli, B. T., \& Zannon, C. M. L. C. (2001). Análise fatorial de uma medida de estratégias de enfrentamento. Psicologia Teoria e Pesquisa, 17(3), 225-234.
Silva, L., Santos, R. C., \& Parada, C. M. G. L. (2004). Compreendendo o significado da gestação para grávidas diabéticas. Revista Latino-Americana de Enfermagem, 12(6), 899-904.

Simpson, E., Mull, J. D., Longley, E., \& East, J. (2000). Pica during pregnancy in low-income women born in Mexico. The Western Journal of Medicine, 173, 20-40.

Soulé, M. (1992). Le psychiatre dans un service de medicine fetale et diagnostic anténatal. In M. Soulé, F. Begoin-Guignard, H. Cohen, F. Daffos, D. David, P. Faure, ... B. Schaal (Eds.), Introduction à la psychiatrie fetale. Les aspects psychologiques et psycopathologiques en medicine fetale et diagnostic prénatal. Paris: ESF.

Thihalolipavan, S., Candalla, B. M., \& Ehrlich, J. (2013). Examining Pica in NYC pregnant women with elevated blood lead levels. Maternal and Child Health Journal, 17, 49-55.

Van Batenburg-Eddes, T., Brion, M. J., Henrichs, J., Jaddoe, V. W. V., Hofman, A., Verhulst, F. C., ...Tiemeier, H. (2013). Parental depressive and anxiety symptoms during pregnancy and attention problems in children: A cross-cohort consistency study. Journal of Child Psychology and Psychiatry, 54(5), 591-600.

Vieira, B., \& Parizotto, A. (2013). Alterações psicológicas decorrentes do período gravídico. Unoesc \& Ciência - ACBS, 4(1), 79-90.

Vythilingum, B. (2008). Anxiety disorders in pregnancy. Current Psychiatry Reports, 10(4), 331335.

Woods, S. M., Melville, J. L., Guo, Y., Fan, M. Y., \& Gavin, A. (2010). Psychosocial stress during pregnancy. American Journal of Obstetrics \& Gynecoly, 202(1), 61, e1-7. 7.

Young, S. L. (2010). Pica in pregnancy: New ideas about an old condition. Annu. Revista de $\mathrm{Nu}$ trição, 30, 403-422. 